\title{
Predicting wood density of growth increments of Douglas-fir stands in New Zealand
}

Peter N. Beets ${ }^{*}$ (D, Mark O. Kimberley, Graeme R. Oliver and Stephen H. Pearce

\begin{abstract}
Background: Douglas-fir comprises $6 \%$ of New Zealand's planted forest area and contributes to the national carbon sequestration estimate. Carbon stock changes in Douglas-fir stem wood can be calculated by multiplying the increment in stem volume under bark by the density of the growth sheath and the carbon fraction. This paper describes a new model developed to predict variation in wood density of Douglas-fir growth sheaths from known wood density drivers.
\end{abstract}

Methods: Datasets used to parameterise the wood density model contained: (1) mean breast height (1.4 m above ground) outerwood (based on $50 \mathrm{~mm}$ long cores) density of 30 trees per stand from 32 semi-mature and mature stands with soil and climate data, for predicting wood basic density from environmental factors; (2) basic density of wood samples taken at breast height and at regular height intervals along the stem of 75 trees from 10 stands, for predicting the weighted mean wood basic density of pre-defined growth sheaths; and (3) breast height pith-tobark radial density profiles based on 500 trees from 47 stands, for predicting wood density of individual annual growth rings at breast height. Linear and non-linear mixed models were developed using these data to explain the variation in wood density of growth sheaths.

Results: Breast height outerwood density was positively related to mean annual air temperature and negatively related to soil nitrogen fertility. This environmental model jointly explaining $83 \%$ of the variation in wood basic density at breast height of ring 30 from the pith. The radial pattern of wood density variation of annual growth rings at breast height was calibrated to a site using predictions from the environmental model. The ratio of growth sheath density to breast height ring density was applied to the predicted density of annual growth rings at breast height. This ratio decreased from 1.05 close to the pith to 0.95 in outerwood rings of mature trees, with ring number from pith explaining $49 \%$ of the variation in this ratio.

Conclusions: A wood density model that incorporates the important drivers of variation in density of stem wood growth sheaths in New Zealand-grown Douglas-fir will improve the accuracy of carbon stock and stock change estimates in NZ's planted forest estate. The new wood density model has been linked to the Forest Carbon Predictor which predicts carbon stocks in live and dead biomass pools from inventory plot measurements, site mean annual temperature, and soil nitrogen fertility information.

Keywords: Stand carbon, Wood density, Pseudotsuga menziesii, Models, Site factors, Soil fertility

\footnotetext{
*Correspondence: peter.beets@scionresearch.com
}

Scion, Private Bag 3020, Rotorua 3046, New Zealand 


\section{Background}

Carbon stocks and stock changes in New Zealand's exotic plantation forest area are estimated in order to meet international reporting commitments under the United Nations Framework Convention on Climate Change and the Kyoto Protocol (IPCC 2003). Assessments of the regional performance of a wide range of exotic tree species planted in New Zealand (Beekhuis and Will 1965) revealed that Pinus radiata D.Don (radiata pine) performs well in most districts that are free of snow, which explains why this species is widely planted throughout New Zealand and currently comprises approximately $90 \%$ of NZ's exotic plantation forest area of 1.7 million ha. In contrast, Pseudotsuga menziesii (Mirb.) Franco (Douglasfir), which currently comprises approximately only $6 \%$ (NEFD 2016), performs best in southern and higher elevation areas where cold temperatures reduce the impact of needle diseases (Stone et al. 2007) on growth. Carbon stocks and stock changes over time are estimated for these species using yield tables derived from an inventory plotbased modelling system called the Forest Carbon Predictor (FCP). The FCP links stem gross and net annual volume increment predictions with estimates of wood density of annual growth sheaths (Beets et al. 2011). For radiata pine, growth sheath density is modelled as a function of site mean annual temperature, soil nitrogen fertility, and stocking (Beets et al. (2007). A growth sheath density model has not been developed for Douglas-fir. However, components of the model developed to predict the density of Douglas-fir $\log$ sections in relation to timber performance (Kimberley et al. 2017) are applicable for the estimation of carbon stock changes over time. This paper describes a model developed to predict variation in wood density of Douglas-fir growth sheaths from known drivers of wood density in New Zealand, identified previously by Kimberley et al. (2017), utilising a combination of new and existing sub-models.

Wood density varies in relation to site mean annual temperature, soil nitrogen fertility, and silvicultural management factors (stocking/thinning), both in radiata pine and Douglas-fir (Erickson and Lambert 1958; Jozsa and Brix 1989; Brix 1993; Beets et al. 2007; Kantavichai et al. 2010; Kimberley et al. 2017). Nitrogen fertiliser trials provide direct evidence linking wood density to nitrogen supply. These trials show that fertiliser applications ephemerally increase foliar nitrogen and reduce wood density of growth rings formed that year (Beets et al. 2001; Jozsa and Brix 1989). By inference, the reduction in wood density with increasing nitrogen fertility of a site, as reflected by the soil carbon $(\mathrm{C})$ nitrogen $(\mathrm{N})$ ratio, $\mathrm{C} /(\mathrm{N}-0.014)$ (Beets et al. 2007), can be ascribed to elevated foliar nitrogen.

Wood density also varies radially and longitudinally within stems. Unlike radiata pine, where wood density increases from pith to bark, Douglas-fir wood density initially decreases in the first 5-7 rings from the pith and then increases beyond ring 10 until attaining a maximum value at around ring 30 from the pith (Jozsa and Brix 1989; Kimberley et al. 2017). Wood density is relatively high near the pith because the density of the early wood is high near the pith in Douglas-fir (Harris and Orman 1958). This radial pattern is evident in Douglas-fir irrespective of height up the stem (Jozsa and Brix 1989).

In this paper, we describe the datasets and model developed to predict variation in wood density of annual growth sheaths from site information.

\section{Methods}

\section{Data collection and modelling approach}

The data requirements and steps used to model the density of growth sheaths laid down annually in Douglas-fir stands largely follow those developed for radiata pine (Beets et al. 2007). The data and modelling are briefly described here and in detail below.

Firstly, breast height $(1.4 \mathrm{~m})$ mean outerwood density was measured in stands sampled across a wide range of sites throughout New Zealand with climate and soil nitrogen fertility information. Outerwood density varies with age but is more-or-less constant from around ring age 30 years. Hence, for modelling purposes, the mean breast height outerwood density of a stand was corrected to growth ring 30 from pith, $D_{30}$, which we refer to as the reference density. The stands sampled for sub-model 1 (described below) ranged in age from 19 to 52 years (with a mean age of 35 years), and hence extrapolation was required to predict the density of the 30th ring of some stands. Given the ages of the stands sampled, less extrapolation is required to remove age effects using ring 30 as the reference age compared to ring 40, which was used by Kimberley et al. (2017). Sub-model 1 uses site mean annual temperature and soil nitrogen fertility as inputs and outputs the reference density.

Secondly, historical data on breast height pith-to-bark density profiles from mature trees sampled from a wide range of sites throughout New Zealand had already been incorporated in a model for predicting the variation in ring density from pith-to-bark (Kimberley et al. 2017). This model, which we refer to as sub-model 2, has two purposes: to predict the reference density used to parameterise sub-model 1 and to provide pith-to-bark density trajectories. Hence, sub-models 1 and 2 allow for the effects of site factors and tree age on breast height density changes at breast height.

Thirdly, the mean wood density of growth sheaths laid down over the entire length of the stem was determined from disc samples cut at fixed intervals along the stems of trees sampled from a number of sites and stand ages. For each growth sheath, the density of the 
corresponding growth ring at breast height was also determined. The ratio of sheath density to the breast height density was calculated for all growth sheaths of each tree. Sub-model 3 predicts the ratios as a function of breast height ring number from pith. The density of annual growth sheaths are obtained for each site by apply the ratios predicted by sub-model 3 to the siteadjusted pith-to-bark density predictions from submodels 1 and 2 .

\section{Development of sub-models}

The density of annual growth sheaths is modelled by combining predictions from the above three sub-models, as follows:

1. Sub-model 1 predicts breast height density of the reference ring (30th ring from the pith), using environmental data as input. The density of the reference ring was predicted from the outerwood density measurements of each stand using submodel 2, and these predicted values used to parameterise sub-model 1.

2. Sub-model 2 predicts wood density of annual growth rings at breast height, numbered from pith to bark. This model was developed in a previous study (Kimberley et al. 2017). Breast height pith-tobark ring density trajectories are derived from density predicted at the reference ring $\left(D_{30}\right)$ from the temperature and soil fertility from sub-model 1 .

3. Sub-model 3 predicts wood density of any stem annual growth sheath given the ring age, by applying the predicted ratio of the sheath density/ breast height ring density to the site and age adjusted predictions of breast height density of that growth ring predicted by sub-models 1 and 2 .

\section{Data requirements for each sub-model} Site effects on breast height outerwood density for parameterising sub-model 1

Sub-model 1 was developed using breast height outerwood density data from 32 stands surveyed in 2011 (Table 1). These stands were growing at sites selected to cover the spatial distribution and site fertility of Douglas-fir across New Zealand. Outerwood density at these sites ranged from 333 to $526 \mathrm{~kg} / \mathrm{m}^{3}$ with a mean of $433 \mathrm{~kg} / \mathrm{m}^{3}$ (Table 2) and were similar in density to data in the national wood density database, which contains data from 312 stands ranging in outerwood density from 319 to $532 \mathrm{~kg} / \mathrm{m}^{3}$, with a mean of $427 \mathrm{~kg} /$ $\mathrm{m}^{3}$ (Kimberley et al. 2017). Because breast height wood density varies considerably from pith to bark (Kimberley et al. 2017), only stands aged 19 years or older were included (Table 1). One outerwood density core was taken at $1.4 \mathrm{~m}$ height from 30 live dominant and co- dominant trees within each stand. Small trees were excluded because volume increment per hectare largely reflects the growth rate of larger trees within a stand. Each core was trimmed to give a 50-mm-long sample of outerwood from immediately under the bark. The number of annual growth rings within each 50-mm-long core sample was recorded and its basic density determined using the maximum moisture content method (Smith 1954).

Data for each stand, including mean ring number from pith, the measured outerwood density, the predicted breast height wood density of ring 30 from pith (reference ring), and site variables are given in Table 2 . The mean number of rings at breast height was calculated for each site by subtracting breast height age (the number of years required for trees to grow to breast height, $1.4 \mathrm{~m}$ ) from stand age. Breast height age was estimated for each stand from site index using a national height/age function for Douglas-fir and ranged from 1.2 to 5.2 years and averaged 2.9 years. The mean ring number from pith of the outerwood core samples was calculated by subtracting half the mean number of rings per core from the mean number of rings at breast height. Because the stands varied in age (Table 1), breast height outerwood density measurements were corrected to ring 30 from pith. This was achieved using sub-model 2 , the breast height radial density model described in Kimberley et al. (2017) and is described in the 'Appendix' section.

Depending on the site, either 20 or $300-5 \mathrm{~cm}$ mineral soil cores were collected systematically from throughout the stand with a Hoffer tube sampler. These soil core samples were bulked and air-dried, and the fine earth fraction $(<2 \mathrm{~mm})$, and carbon and nitrogen analysed using a Leco CNS-2000 furnace (LECO Corp., St Joseph, MI, USA). Site mean annual air temperature was estimated from the National Institute of Water and Atmospheric Research (NIWA) climate surfaces.

\section{Breast height pith-to-bark density profiles and density of the 30th ring from pith for parameterising sub-model 2} Sub-model 2 was developed from breast height pith-tobark radial wood density core data, which were compiled and published by Kimberley et al. (2017). The 5-mmdiameter core samples were available for approximately 500 trees from 47 stands. Cores were Soxhlet extracted with methanol to remove extractives and resin, a strip milled from each core, and the strips scanned using the X-ray densitometer at Scion (Cown and Clement 1983).

\section{Density of stem wood growth sheaths and of the corresponding rings at breast height for parameterising sub-model 3}

Sub-model 3 was developed using wood density data from eight stands, six of which ranged in age from 9 to 31 years (Table 3). Stand attributes determined at these 
Table 1 Location and age of Douglas-fir stands sampled in a national wood density survey used to develop sub-model 1

\begin{tabular}{|c|c|c|c|c|c|c|}
\hline Site number & Location or forest & Stand age (years) & Latitude $\left({ }^{\circ} \mathrm{S}\right)$ & Longitude $\left({ }^{\circ} \mathrm{E}\right)$ & Elevation $(\mathrm{m})$ & Stocking (stems/ha) \\
\hline 1 & Arrowtown & 27 & 44.94 & 168.77 & 495 & 450 \\
\hline 2 & Ribbonwood & 28 & 44.38 & 169.82 & 650 & 500 \\
\hline 3 & Glenfoyle & 30 & 44.72 & 169.33 & 400 & 633 \\
\hline 4 & Castledowns & 26 & 45.85 & 168.20 & 500 & 490 \\
\hline 5 & Tokoiti & 24 & 46.16 & 169.97 & 70 & 463 \\
\hline 6 & Gwavas & 52 & 39.71 & 176.37 & 486 & 558 \\
\hline 7 & Dusky & 27 & 45.85 & 169.12 & 300 & 490 \\
\hline 8 & Te Wera & 42 & 39.19 & 174.63 & 214 & 580 \\
\hline 9 & Whakarewarewa & 28 & 38.21 & 176.27 & 420 & 650 \\
\hline 10 & Berwick & 30 & 45.87 & 170.02 & 530 & 490 \\
\hline 11 & Kinleith & 52 & 38.38 & 175.87 & 443 & 537 \\
\hline 12 & Rotoehu & 39 & 37.98 & 176.52 & 266 & 433 \\
\hline 13 & Kaingaroa & 52 & 38.45 & 176.60 & 438 & 537 \\
\hline 14 & Rotoehu & 52 & 37.91 & 176.58 & 91 & 550 \\
\hline 15 & Hanmer & 27 & 42.53 & 172.91 & 520 & 490 \\
\hline 16 & Wairoa & 31 & 38.98 & 177.56 & 350 & 488 \\
\hline 17 & Kaingaroa & 28 & 38.89 & 176.29 & 780 & 500 \\
\hline 18 & Rankleburn & 52 & 45.99 & 169.42 & 150 & 176 \\
\hline 19 & Kaingaroa & 20 & 38.38 & 176.71 & 255 & 533 \\
\hline 20 & Craigieburn & 32 & 43.15 & 171.73 & 800 & 500 \\
\hline 21 & St Arnaud & 28 & 41.76 & 172.79 & 560 & 575 \\
\hline 22 & Tauhara & 23 & 38.70 & 176.23 & 550 & 633 \\
\hline 23 & BurntFace6 & 44 & 43.04 & 171.64 & 1080 & 650 \\
\hline 24 & BurntFace1 & 46 & 43.04 & 171.63 & 800 & 520 \\
\hline 25 & BurntFace5 & 46 & 43.04 & 171.63 & 960 & 640 \\
\hline 26 & BurntFace3 & 46 & 43.04 & 171.63 & 850 & 680 \\
\hline 27 & North Bank & 29 & 41.47 & 173.67 & 200 & 700 \\
\hline 28 & Golden Downs & 52 & 41.46 & 172.91 & 413 & 638 \\
\hline 29 & Kaingaroa & 21 & 38.88 & 176.29 & 790 & 1375 \\
\hline 30 & Forest Creek & 19 & 43.69 & 170.88 & 737 & 1080 \\
\hline 31 & Kaingaroa & 28 & 38.34 & 176.39 & 367 & 800 \\
\hline 32 & Whakarewarewa & 31 & 38.21 & 176.28 & 440 & 717 \\
\hline
\end{tabular}

six stands were based on a 0.04-ha sample plot installed at each site. Diameter at breast height of all trees in the plot and the height of a random sample of no less than 20 dominant or co-dominant trees were measured. Eight to 10 dominant or co-dominant trees per plot were selected across the dbh range and felled, individual tree biomass measured, and stand biomass determined (Beets, P.N., Oliver, G.R., Pearce, S.H., Kimberley, M.O., Henley, D. G., \& Meason, D.F. Species-specific adjustment function for the Forest Carbon Predictor. New Zealand Journal of Forestry Science (submitted)). Disc sampling points were marked at pre-determined height intervals along each stem, starting nominally at the base $(0.15 \mathrm{~m}$ height $)$ and thereafter at either $1 \mathrm{~m}$ (9- and 10-year-old stands), $2 \mathrm{~m}$ (19- and 21-year-old stands), or $3 \mathrm{~m} \mathrm{(28}$ and 31-year-old stands) intervals along the stem to the top of the tree. A 5-cm-thick disc sample was cut at each stem sample height (except the base, where a 2.5 -cm-thick disc was taken to ensure appropriate weighting of samples when calculating sheath density).

Wood density of growth sheaths was determined from sector samples. Two $40^{\circ}$ opposing sectors were cut from each disc, and each sector divided into ring groups comprised of either two ring (in the 9- and 10-year-old trees) or five ring groups (trees older than 10 years). The density of wood samples was determined following standard 
Table 2 Outerwood basic density of 50-mm core samples, mean ring number from pith, predicted basic density of ring 30 from pith, and environmental variables at 32 Douglas-fir sites used to develop sub-model 1

\begin{tabular}{|c|c|c|c|c|c|c|c|}
\hline $\begin{array}{l}\text { Site } \\
\text { number }\end{array}$ & $\begin{array}{l}\text { Mean ring number } \\
\text { from pith }\end{array}$ & $\begin{array}{l}\text { Measured outerwood } \\
\text { density }\left(\mathrm{kg} \mathrm{m}^{-3}\right)\end{array}$ & $\begin{array}{l}\text { Predicted wood density of reference ring (ring } 30 \\
\text { from pith) }\left(\mathrm{kg} \mathrm{m}^{-3}\right)\end{array}$ & $\begin{array}{l}\text { Mean annual } \\
\text { temperature }\left({ }^{\circ} \mathrm{C}\right)\end{array}$ & $\begin{array}{l}\text { Soil C } \\
(\%)\end{array}$ & $\begin{array}{l}\text { Soil N } \\
(\%)\end{array}$ & $\begin{array}{l}\text { Soil } C /(N- \\
0.014)\end{array}$ \\
\hline 1 & 19.2 & 384 & 399 & 8.9 & 2.53 & 0.200 & 13.6 \\
\hline 2 & 20.1 & 386 & 398 & 7.9 & 4.36 & 0.307 & 14.9 \\
\hline 3 & 21.8 & 393 & 399 & 10.3 & 3.09 & 0.214 & 15.5 \\
\hline 4 & 18.8 & 319 & 333 & 7.8 & 5.57 & 0.380 & 15.2 \\
\hline 5 & 16.9 & 408 & 430 & 10.1 & 3.56 & 0.235 & 16.1 \\
\hline 6 & 36.8 & 426 & 423 & 10.9 & 11.56 & 0.749 & 15.7 \\
\hline 7 & 18.1 & 381 & 397 & 9.6 & 5.46 & 0.342 & 16.6 \\
\hline 8 & 27.4 & 491 & 491 & 12.0 & 13.15 & 0.757 & 17.7 \\
\hline 9 & 15.8 & 493 & 526 & 12.2 & 6.14 & 0.352 & 18.2 \\
\hline 10 & 21.8 & 369 & 376 & 8.1 & 5.17 & 0.295 & 18.4 \\
\hline 11 & 42.1 & 444 & 440 & 11.7 & 10.85 & 0.612 & 18.1 \\
\hline 12 & 29.2 & 489 & 489 & 12.5 & 4.64 & 0.262 & 18.7 \\
\hline 13 & 40.3 & 454 & 450 & 11.5 & 5.99 & 0.334 & 18.7 \\
\hline 14 & 38.1 & 497 & 494 & 13.3 & 6.51 & 0.361 & 18.8 \\
\hline 15 & 19.9 & 406 & 420 & 9.8 & 1.99 & 0.107 & 21.4 \\
\hline 16 & 24.2 & 461 & 466 & 11.3 & 3.12 & 0.166 & 20.5 \\
\hline 17 & 19.6 & 421 & 437 & 9.5 & 5.18 & 0.262 & 20.9 \\
\hline 18 & 43.3 & 420 & 415 & 9.8 & 5.61 & 0.279 & 21.2 \\
\hline 19 & 14.3 & 446 & 482 & 12.9 & 4.43 & 0.217 & 21.8 \\
\hline 20 & 23.3 & 369 & 372 & 8.3 & 4.25 & 0.205 & 22.3 \\
\hline 21 & 20.6 & 411 & 422 & 9.4 & 4.94 & 0.230 & 22.9 \\
\hline 22 & 15.9 & 419 & 447 & 10.8 & 6.70 & 0.290 & 24.3 \\
\hline 23 & 31.3 & 366 & 361 & 7.3 & 11.09 & 0.452 & 25.3 \\
\hline 24 & 34.7 & 420 & 415 & 7.9 & 3.57 & 0.144 & 27.5 \\
\hline 25 & 34.1 & 401 & 396 & 7.6 & 4.15 & 0.166 & 27.3 \\
\hline 26 & 34.4 & 418 & 413 & 7.6 & 4.19 & 0.156 & 29.5 \\
\hline 27 & 21.1 & 485 & 495 & 11.6 & 3.38 & 0.117 & 32.8 \\
\hline 28 & 39.5 & 505 & 501 & 10.4 & 3.79 & 0.129 & 33.0 \\
\hline 29 & 12.8 & 373 & 412 & 9.3 & 6.86 & 0.322 & 22.3 \\
\hline 30 & 13.6 & 362 & 403 & 8.2 & 3.99 & 0.234 & 18.1 \\
\hline 31 & 23.7 & 488 & 493 & 11.9 & 6.25 & 0.328 & 19.9 \\
\hline 32 & 26.5 & 462 & 463 & 12.0 & 8.04 & 0.424 & 19.6 \\
\hline
\end{tabular}

methods (Cown et al. 1991). Briefly, this involved measuring the volume of each wood sample using water displacement and its oven dry weight following drying at $105^{\circ} \mathrm{C}$. Growth sheath density was calculated by dividing the total dry weight of sector samples representing each ring group by the corresponding volume of the sector samples.

In addition to the six stands with biomass measurements, data from two mature Douglas-fir stands sampled in a wood properties study in 1993 were included to extend the age range available for analysis. Disc samples were cut at $5-\mathrm{m}$ intervals along the stem from 11 trees in a 33-year-old stand at Waiotapu and 14 trees from a 59year-old stand in Waimahia. Measurements of ring width and wood density were obtained using X-ray densitometry of strips cut from discs at Scion (Cown and Clement 1983), as in sub-model 2. Breast height measurements of outerwood density were obtained using 50-mm-long cores. The density of growth sheaths was represented by the number of rings in the breast height outerwood cores (the outer 10 rings at Waiotapu and outer 21 rings at Waimahia). Mean density of the growth sheath was calculated as a weighted average of the required rings across all disc heights, weighted by ring area.

The calculated ratios of sheath density to breast height ring density for sub-model 3 were based on trees sampled from juvenile and mature stands because sub-model 3 is intended to be applied to stands of any age. 
Table 3 Stand attributes, site characteristics, and wood density in Douglas-fir stands used to develop sub-model 3

\begin{tabular}{|c|c|c|c|c|c|c|c|}
\hline Attribute & Units & $\begin{array}{l}\text { Gowan } \\
\text { Hill } \\
10 \text { years }\end{array}$ & $\begin{array}{l}\text { Kaingaroa } \\
21 \text { years }\end{array}$ & $\begin{array}{l}\text { Forest Creek } \\
9 \text { years }\end{array}$ & $\begin{array}{l}\text { Forest Creek } \\
19 \text { years }\end{array}$ & $\begin{array}{l}\text { Kaingaroa } \\
28 \text { years }\end{array}$ & $\begin{array}{l}\text { Whakarewarewa } \\
31 \text { years }\end{array}$ \\
\hline Year planted & & 1998 & 1985 & 2000 & 1990 & 1982 & 1979 \\
\hline Initial stocking & $\begin{array}{l}\text { Stems/ } \\
\text { ha }\end{array}$ & 1600 & 1450 & 1419 & 1372 & 1666 & 2000 \\
\hline Stand age & Years & 10 & 21 & 9 & 19 & 28 & 31 \\
\hline Live stocking at assessment age & $\begin{array}{l}\text { Stems/ } \\
\text { ha }\end{array}$ & 1186 & 1250 & 1419 & 1051 & 800 & 717 \\
\hline Basal area & $\mathrm{m}^{2} / \mathrm{ha}$ & 24.8 & 52.6 & 12.0 & 37.9 & 55.5 & 46.7 \\
\hline Mean top height & $\mathrm{m}$ & 8.4 & 15.5 & 6.5 & 14.7 & 25.6 & 26.2 \\
\hline Average ring age of outerwood & years & 7.5 & 15.5 & 6.5 & 16.5 & 25.5 & 28.5 \\
\hline $\begin{array}{l}\text { Breast height wood density of outer } 5 \text { rings of plot trees } \\
\text { (and sample size) }\end{array}$ & $\mathrm{kg} / \mathrm{m}^{3}$ & $336(20)$ & $373(20)^{*}$ & $388(36)$ & $362(23)$ & $488(8)$ & $462(35)$ \\
\hline Elevation & $\mathrm{m}$ & 254 & 790 & 786 & 737 & 367 & 440 \\
\hline Mean annual temperature & ${ }^{\circ} \mathrm{C}$ & 9.8 & 9.4 & 8.0 & 8.2 & 11.9 & 12.0 \\
\hline C (0-5 cm soil) & $\%$ & 5.6 & 6.9 & 5.3 & 4.0 & 6.3 & 8.0 \\
\hline N (0-5 cm soil) & $\%$ & 0.41 & 0.32 & 0.37 & 0.23 & 0.33 & 0.42 \\
\hline$C /(\mathrm{N}-0.014)$ & & 14.1 & 22.3 & 14.9 & 18.1 & 19.9 & 19.6 \\
\hline
\end{tabular}

*Mean of 50 -mm cores with average ring age of outerwood based on diameter increment of the 10 biomass trees

\section{Statistical analysis}

\section{Sub-model 1}

Pearson correlation and partial correlation coefficients between measured breast height density of outerwood $\left(D_{\text {ow }}\right)$ and site mean annual temperature, MAT, soil nitrogen fertility index, $\mathrm{C} /(\mathrm{N}-0.014)$ (following Beets et al. 2007), and ring number from pith, $R$, were calculated using the CORR procedure in SAS Version 9.3. Correlations using the predicted breast height density of ring 30 from pith $\left(D_{30}\right)$ were also examined to determine whether this variable eliminated any age-related correlation. The following multiple linear regression model was then fitted using the SAS GLM procedure for predicting $D_{30}$ from mean annual temperature and soil C/ $(\mathrm{N}-0.014)$ ratio:

$$
\begin{aligned}
\text { Sub-model 1: } D_{30 i}= & a 1+b 1 \times M A T_{i}+c 1 \\
& \times C \% /(N \%-0.014)_{i} \\
& +e_{i}
\end{aligned}
$$

where $D_{30 \mathrm{i}}$ is breast height wood density at ring 30 from pith $\left(\mathrm{kg} \mathrm{m}^{-3}\right)$ for site $i$, derived using sub-model 2 from outerwood density measurements, $\mathrm{MAT}_{i}$ is mean annual temperature for stand $i$, the adjusted $\mathrm{C}: \mathrm{N}$ ratio, $\mathrm{C} /(\mathrm{N}-$ $0.014)$, is based on $\mathrm{C}$ and $\mathrm{N}$ in the upper $5 \mathrm{~cm}$ of mineral soil, $a 1, b 1$, and $c 1$ are regression coefficients, and $e_{i}$ is the error term assumed to be independently and identically, normally distributed with mean zero. The model was tested to determine whether significant differences in the relationship in either intercept or slope parameters existed between North and South Island stands and between stands planted prior to and after 1990.

\section{Sub-model 2}

The development of sub-model 2 is fully described in Kimberley et al. (2017). For our purposes, sub-model 2 was initially used to adjust the breast height outerwood density measurements of stands used to parameterise sub-model 1 to the 30th growth ring from the pith. This adjustment was necessary to remove the effects of stand age on outerwood density measurements. The main use of sub-model 2 is to predict breast pith-to-bark ring density profiles, after taking into account the site determined predictions of outerwood density (30th ring from pith) from sub-model 1, as described in the 'Appendix' section.

\section{Sub-model 3}

A mixed model was used to predict the ratio of growth sheath to breast height wood density as a function of breast height ring from pith, fitted using the SAS MIXED procedure. Various transformations of the independent variable were tested for inclusion in the model including untransformed (linear), square root, and log. The square root transformation provided the best fit and was therefore chosen for the final model which was of the following form:

$$
\begin{aligned}
\text { Sub-model } 3: & \left(D S_{R} / D_{R}\right)_{i j} \\
= & a 3+b 3 \times \sqrt{R_{i j}}+s_{i}+e_{i j}
\end{aligned}
$$

where $\left(D S_{R} / D_{R}\right)_{i j}$ is the ratio of sheath density to breast height density for sheath $j$ in stand $i, R_{i j}$ is breast height ring-from-pith, $a 3$ and $b 3$ are model coefficients, $s_{i}$ is a random error term representing stand $i$, and $e_{i j}$ is the residual error term with both error terms assumed to be 
independently and identically, normally distributed with mean zero.

\section{Results}

Sub-model 1-prediction of breast height wood density of ring $\mathbf{3 0}$ from pith from site variables

Measured breast height density of outerwood, $D_{\text {ow, }}$, was strongly positively correlated with mean annual temperature $(r=0.82)$ and weakly correlated with stand age $(r=0.36)$ (Table 4$)$. Moreover, $D_{\text {ow }}$ was significantly correlated with soil $\mathrm{C} /(\mathrm{N}-0.014)$ only after accounting for temperature and age effects, with a partial correlation of 0.62 (Table 4). Defining outerwood density as the predicted density of ring 30 from pith, $D_{30}$ (the reference ring), using the pith-to-bark density profile model described in Kimberley et al. (2017), eliminated stand age effects. Relationships between breast height wood density at ring 30 from pith and mean annual temperature and soil $\mathrm{C} /(\mathrm{N}-0.014)$ are shown in Fig. 1.

The regression model that predicts wood density at breast height in ring 30 from pith from mean annual temperature and the adjusted soil $\mathrm{C}: \mathrm{N}$ ratio (i.e. $\mathrm{C} /(\mathrm{N}-$ 0.014 ) explained $83 \%$ of the variation in density. Parameter estimates are given in Table 5 . Tests were made to determine whether separate intercept or slope parameters were required for North and South Islands, or for stands planted before and after 1990, but no significance differences in the relationship were found for these factors.

Sub-model 2-breast height pith-to-bark radial density data While already published in Kimberley et al. (2017), for completeness, the functions are also provided in the 'Appendix' section of our paper, which describes firstly how $D_{30}$ is derived when parameterising sub-model 1 , and secondly how breast height pith-to-bark ring density predictions are adjusted using sub-model 2 for the

Table 4 Correlations between Douglas-fir basic wood density, temperature (MAT), soil $C /(N-0.014)$, and ring number $(R)$, based from 32 sites throughout New Zealand. The wood density variables analysed include the measured breast height outerwood density $\left(D_{\text {ow }}\right)$ and predicted outerwood density of ring 30 from pith $\left(D_{30}\right)$. The table shows wood density Pearson correlations $(r)$ with each variable and partial correlations with each variable adjusted for the other two variables (partial $r$ )

\begin{tabular}{llllll}
\hline Variable & \multicolumn{2}{l}{$D_{\text {ow }}$} & & $D_{30}$ & \\
\cline { 2 - 3 } \cline { 5 - 6 } & $r$ & Partial $r$ & & $r$ & Partial $r$ \\
\hline MAT & $0.82^{* *}$ & $0.90^{* *}$ & $0.85^{* *}$ & $0.91^{* *}$ \\
$C /(\mathrm{N}-0.014)$ & 0.26 & $0.62^{* *}$ & 0.21 & $0.64^{* *}$ \\
$R$ & $0.36^{*}$ & $0.40^{*}$ & 0.11 & -0.16 \\
\hline \multicolumn{2}{l}{ Statistical significance indicated by ${ }^{*}(p<0.05)$ and ${ }^{* *}(p<0.01)$}
\end{tabular}

effects of site factors which are predicted using submodel 1.

Sub-model 3-ratios for predicting the density of growth sheaths from breast height ring density

The mean basic density of wood laid down in growth sheaths over the entire stem and at breast height of defined groups of rings are summarised for each stand in Table 6 . The ratio of wood density of the growth sheath to the breast height density was greater than one for the inner 10 rings from pith, but less than one beyond ring 10 (Fig. 2).

The regression model represented by Eq. 2 predicts the growth sheath density/breast height ring density ratio from the breast height ring number from pith. This model explained $49 \%$ of the variation in the ratio. Parameter estimates for sub-model 3 (Eq. 2) are given in Table 7.

\section{Discussion}

Studies of regional differences in Douglas-fir wood density have identified elevation, temperature, rainfall, soil, and silvicultural factors as drivers of wood density in New Zealand and elsewhere (Erickson and Lambert 1958; Jozsa and Brix 1989; Brix 1993; Beets et al. 2001; Kantavichai et al. 2010; Kimberley et al. 2017). Two important environmental drivers influencing wood density variation in New Zealand-grown Douglas-fir and radiata pine are mean annual temperature and nitrogen fertility of the site, while stocking/thinning has a small effect on density (Kimberley et al. 2017). The importance of nitrogen supply on wood density was clearly demonstrated for radiata pine growing on nitrogen-deficient coastal dunes, where nitrogen inputs from mineral fertiliser applications and legumes decreased wood density and latewood percent (Beets et al. 2001). The influence of temperature on density was more evident in overseas studies than in New Zealand, where historic surveys of breast height outerwood density did not find a relationship with temperature. This unexpected result was previously ascribed to confounding owing to seedlot differences in density, as discussed by Kimberley et al. (2017). The most recent compilation and analysis has clearly shown that temperature is the main climatic factor determining outerwood density variation in New Zealand, and that the fertility of the site is also relevant (Kimberley et al. 2017).

The effect of nitrogen fertility on density, reported in Kimberley et al. (2017), was based on 18 sites, all of which were located in the South Island of New Zealand. Our analysis of the effect of soil fertility on outerwood density, which includes an allowance for stand age effects on outerwood density using $D_{30}$, is based on 32 widely dispersed sites throughout both islands of New Zealand. 

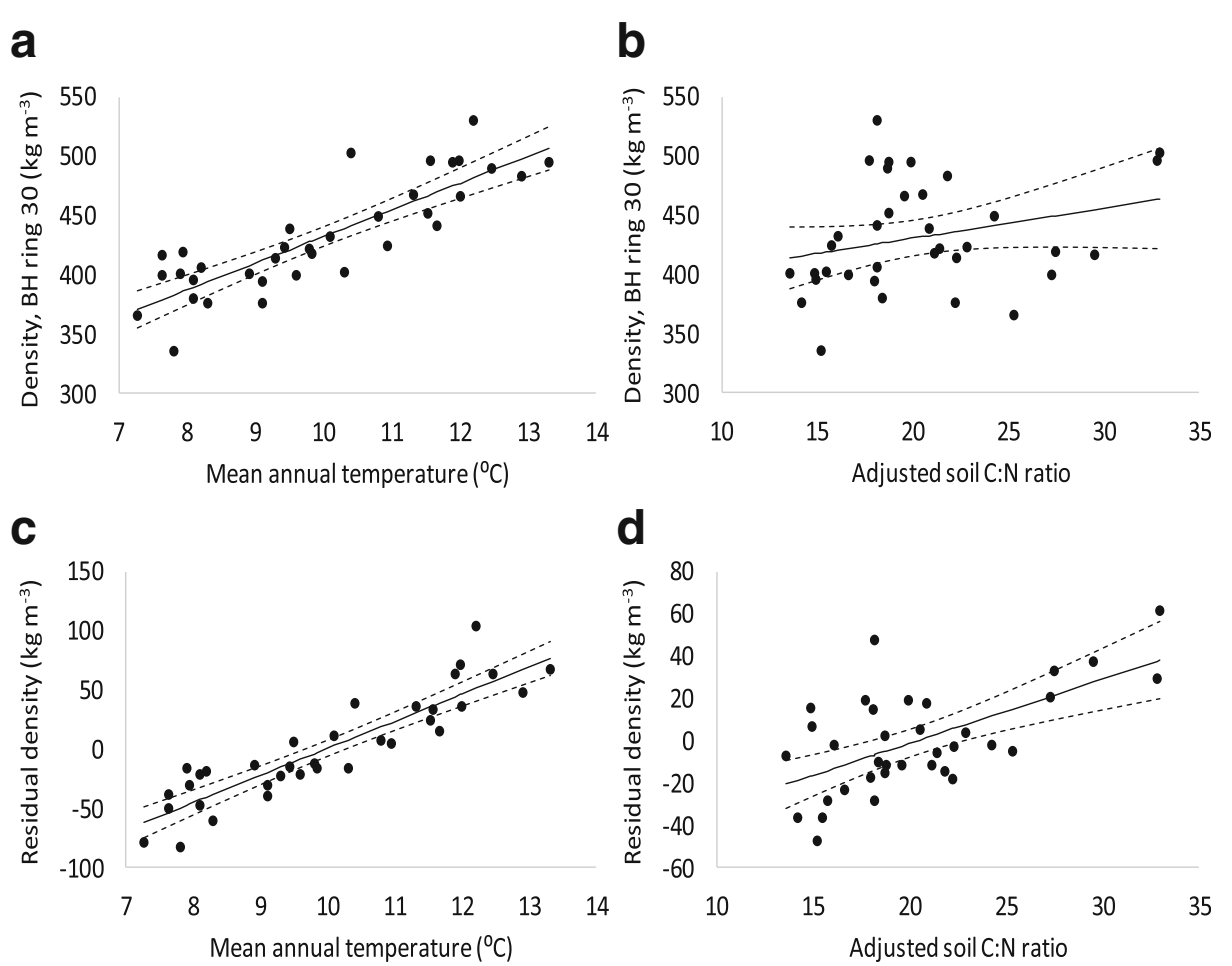

Fig. 1 Relationships between the predicted breast height wood density of ring 30 from pith and temperature and adjusted soil C:N ratio (i.e. C/ $(\mathrm{N}-0.014)$. a Wood density vs mean annual temperature. $\mathbf{b}$ Wood density vs adjusted soil $\mathrm{C}: \mathrm{N}$ ratio. $\mathbf{c}$ residuals from wood density $=a+$ $b \times$ (adjusted soil C:N ratio) regression vs mean annual temperature. $\mathbf{d}$ Residuals from wood density $=a+b \times($ mean annual temperature) regression vs adjusted soil C:N ratio

Analysis of this more comprehensive dataset indicates that the difference in mean density between the North and South Islands, reported in Kimberley et al. (2017), was likely a result of differences in site fertility. The new model incorporates the effects of temperature and nitrogen fertility on wood density and can therefore be confidently applied to Douglas-fir stands growing throughout New Zealand.

The wood density of annual growth sheaths is predicted by multiplying the growth ring density at breast height by the ratio of sheath density/breast height density of the corresponding growth ring. This ratio is moderately stable, although it declined, on average, from 1.05 to 0.95 with increasing ring age. The ratio exceeds 1.0 in small trees and

Table 5 Parameter estimates for sub-model 1. The model predicts breast height wood density in ring 30 from pith $\left(D_{30}\right)$ from mean annual temperature (MAT) and soil $\mathrm{C} /(\mathrm{N}-0.014)$, and was fitted to Douglas-fir data from 32 sites throughout New Zealand. The model $R^{2}=0.83$ and root mean square error $=19.7 \mathrm{~kg} \mathrm{~m}^{-3}$

\begin{tabular}{lllll}
\hline Parameter & Estimate & Std. error & $t$ value & $p$ value \\
\hline al & 136.5 & 24.0 & 5.05 & $<0.0001$ \\
b1 & 23.3 & 2.0 & 11.56 & $<0.0001$ \\
c1 & 3.09 & 0.72 & 4.29 & $<0.0001$ \\
\hline
\end{tabular}

in rings near the pith of mature trees, when proportionally more of the wood of the corresponding growth sheath is below breast height. Conversely, the ratio averages 0.95 in the outer growth rings of mature trees when proportionally more of the wood of a growth sheath is above breast height. Clearly, wood density within a growth sheath decreases with height up the stem. This conclusion is supported by the finding that wood density of log sections decreases with height (Kimberley et al. 2017).

The wood density model is intended to be applied to stands that are not being fertilised. The adjusted soil $\mathrm{C} /$ $\mathrm{N}$ ratio reflects the effects of land use history differences on soil nitrogen fertility and hence on wood density. Use of this model therefore implies that all rings from pithto-bark have low density if the outerwood density is low, or conversely, that all rings will have a high density if the outerwood density is high. This site-determined pattern is clearly evident in the within-tree density trends illustrated in Kimberley et al. (2017). In contrast, fertilised stands exhibit an ephemeral reduction in wood density of between 5 and $16 \%$, which persists as long as foliar $\mathrm{N}$ levels are elevated in response to fertilisation (Jozsa and Brix 1989; Erickson and Lambert 1958; Erickson and Harrison 1974). Given the generally ephemeral nature of foliar responses to fertiliser additions, applying the new 
Table 6 Mean basic density at breast height and mean basic density of growth sheaths for given groups of rings (counted from bark), and the sheath/breast height (BH) density ratio for eight Douglas-fir stands in New Zealand

\begin{tabular}{|c|c|c|c|c|c|}
\hline Site and stand age of biomass trees ( $N$ is sample size) & Rings from bark & Mean ring from pith & Sheath density & $\mathrm{BH}$ density & Sheath/BH density ratio \\
\hline \multirow[t]{2}{*}{ Forest Creek age 9 years $(N=8)$} & $1-3$ & 6 & 373 & 350 & 1.068 \\
\hline & $4-8$ & 3 & 401 & 415 & 0.960 \\
\hline \multirow[t]{3}{*}{ Forest Creek age 19 years $(N=8)$} & $1-5$ & 14 & 370 & 373 & 0.999 \\
\hline & $6-10$ & 9 & 356 & 349 & 1.026 \\
\hline & $11-17$ & 4 & 418 & 419 & 0.993 \\
\hline \multirow[t]{4}{*}{ Gowan Hill age 10 years $(N=8)$} & $1-2$ & 7 & 370 & 344 & 1.082 \\
\hline & $3-4$ & 5 & 355 & 330 & 1.078 \\
\hline & $5-6$ & 3 & 403 & 370 & 1.093 \\
\hline & $7-10$ & 1 & 408 & 400 & 1.020 \\
\hline \multirow[t]{3}{*}{ Kaingaroa age 21 years $(N=10)$} & $1-5$ & 16 & 399 & 442 & 0.906 \\
\hline & $6-10$ & 11 & 362 & 367 & 0.988 \\
\hline & $11-17$ & 6 & 366 & 374 & 0.983 \\
\hline \multirow[t]{5}{*}{ Kaingaroa age 28 years $(N=8)$} & $1-5$ & 24 & 472 & 488 & 0.969 \\
\hline & $6-10$ & 19 & 445 & 456 & 0.976 \\
\hline & $11-15$ & 14 & 463 & 463 & 1.004 \\
\hline & $16-20$ & 9 & 411 & 399 & 1.033 \\
\hline & $21-30$ & 4 & 450 & 439 & 1.036 \\
\hline \multirow[t]{6}{*}{ Whakarewarewa age 31 years $(N=8)$} & $1-5$ & 27 & 453 & 485 & 0.938 \\
\hline & $6-10$ & 22 & 413 & 436 & 0.950 \\
\hline & $11-15$ & 17 & 417 & 444 & 0.939 \\
\hline & $16-20$ & 12 & 398 & 398 & 1.002 \\
\hline & $21-25$ & 7 & 430 & 397 & 1.081 \\
\hline & $26-30$ & 2 & 460 & 423 & 1.087 \\
\hline Waiotapu age 33 years $(N=11)$ & $1-10$ & 26 & 383 & 403 & 0.950 \\
\hline Waimahia age 59 years $(N=14)$ & $1-20$ & 47 & 434 & 469 & 0.925 \\
\hline
\end{tabular}

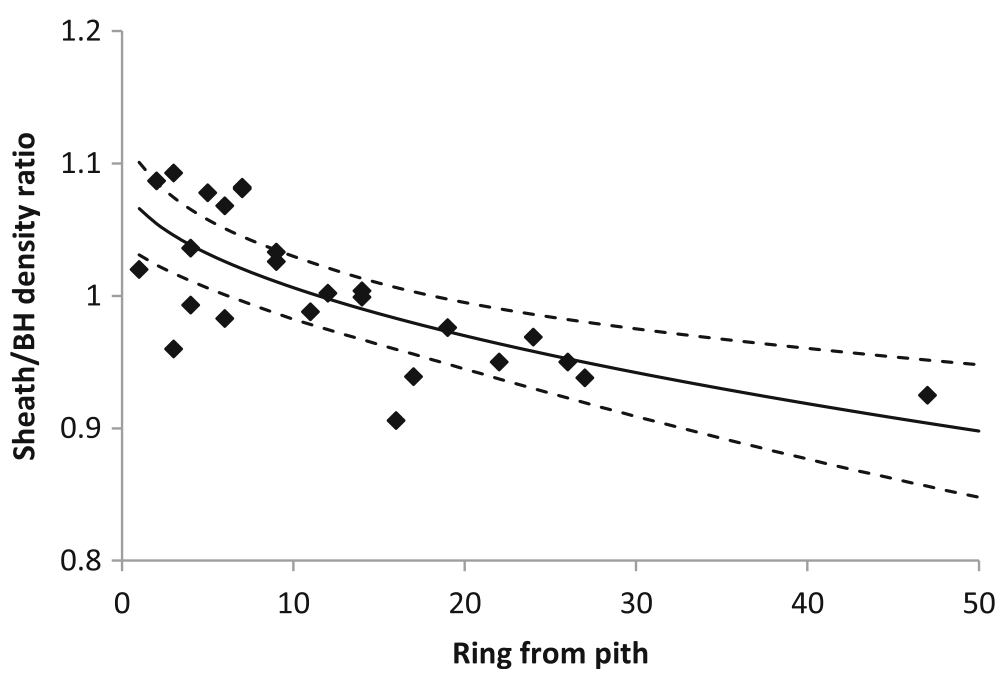

Fig. 2 Relationships between the sheath/BH density ratio and ring number from pith, overlaid with the regression model represented by Eq. 2 and $95 \%$ confidence intervals 
Table 7 Parameter estimates for sub-model 3. The model predicts the sheath to breast height wood density ratio as a function of breast height ring number from pith, and was fitted to Douglas-fir data from eight sites in New Zealand. The model $R^{2}$ $=0.49$

\begin{tabular}{lllll}
\hline Parameter & Estimate & Std. error & $t$ value & $p$ value \\
\hline a3 & 1.094 & 0.021 & 51.15 & $<0.0001$ \\
b3 & -0.0277 & 0.0059 & -4.67 & 0.042
\end{tabular}

wood density model, which was developed using data from unfertilised stands, to fertilised stands is unlikely to lead to significant prediction errors.

The new Douglas-fir density model is similar to the growth sheath density model developed for radiata pine (Beets et al. 2007), where wood density is also modelled as a function of ring age, site mean annual temperature, and nitrogen fertility. As in radiata pine, diameter growth rate significantly influences ring density in Douglas-fir; however, this effect was materially unimportant, in carbon stock terms, although statistically significant in Douglas-fir (Kimberley et al. 2017), and hence was excluded from the model. The new wood density model for Douglas-fir replaces a preliminary version of the model in the FCP that overestimated wood density by approximately $5 \%$. In the FCP, stem volume increment predictions from the 500 Index growth model (Knowles 2005) are multiplied by the density of the corresponding 'growth sheaths' to give annual stem wood dry matter increments in Douglas-fir ${ }^{1}$. Stem dry matter increments are expanded to total dry matter in live and dead organic matter pools using C_Change (Beets et al. 1999).

\section{Conclusion}

This study has shown that site mean annual temperature and soil nitrogen fertility are important environmental drivers of variation in stem wood density of Douglas-fir in New Zealand. The new wood density model has been linked to the Forest Carbon Predictor, which uses site mean annual temperature, soil nitrogen fertility data, and tree measurements from national inventory plots to improve the accuracy of carbon stock estimates for New Zealand's planted forest estate.

\section{Endnotes}

${ }^{1}$ Beets, P.N., Oliver, G.R., Pearce, S.H., Kimberley, M.O., Henley, D. G., \& Meason, D.F. Species-specific adjustment function for the Forest Carbon Predictor. New Zealand Journal of Forestry Science (submitted).

\section{Appendix}

Estimation of basic wood density at breast height in ring 30 from pith in New Zealand Douglas-fir

Sub-model 2 was applied for two distinct modelling purposes:

1. Equations 3 and 4, described in Kimberley et al. (2017), can be used to predict basic wood density at breast height $\left(D_{R}\right)$ as a function of ring number from pith $(R)$ :

$$
\begin{aligned}
D_{R}= & a+(b-R) /(c+d \times \exp (R f)) \\
& +(1-g \times \exp (-R h)) \times L
\end{aligned}
$$

Parameters are given in Table 8 in the 'Appendix' section. The pith-to-bark density profile provided by submodel 2 is calibrated to a site using the parameter $L$. To predict $D_{R}$ at $D_{30}$ (the outerwood density predicted using sub-model 1 in this paper), $L$ is calculated using:

$$
L=D_{30}-(a+(b-30) /(c+d \times \exp (30 f))) /(1-g \times \exp (-30 h))
$$

2. This approach can also be used to estimate $L$ from an outerwood density measurement $\left(D_{\text {core }}\right)$ of a stand, and was used in the current study to predict $D_{30}$ for each of the sites used to develop sub-model 1. In this case, values of $L_{R}$ are calculated for each ring $R$ in the core using:

$$
L_{R}=D_{\text {core }}-(a+(b-R) /(c+d \times \exp (R f))) /(1-g \times \exp (-R h))
$$

The $L_{R}$ are averaged over all rings in the core to give $L$ which is used in Eq. 3 to predict $D_{30}$.

Table 8 Parameter values used in sub-model 2 (from Table 7, Kimberley et al. 2017)

\begin{tabular}{ll}
\hline Parameter & Value \\
\hline$a$ & 432.6 \\
$b$ & 1.22 \\
$c$ & 0.0235 \\
$d$ & 0.0125 \\
$f$ & 0.221 \\
$g$ & 0.814 \\
$h$ & 0.258 \\
\hline
\end{tabular}




\section{Abbreviations}

$a, b, c, d, f, g, h$ : Sub-model 2 coefficients (see Appendix); $a 1, b 1, c 1$ : Submodel 1 coefficients; a3, b3: Sub-model 3 coefficients; BH: Breast height; C: Carbon; $C /(N-0.014)$ : Adjusted carbon to nitrogen ratio; $D_{30}$ : Breast height wood density at ring 30 from pith; $D_{\text {ow: }}$ : Breast height density of outerwood; $D_{R}$ : Breast height wood density at ring $R$ from pith; $D S_{R}$ : Wood density of growth Sheath at ring $R$ from pith; FCP: Forest Carbon Predictor; $i$ : The $i^{\text {th }}$ stand; IPCC: Intergovernmental Panel on Climate Change; $j$ : The $j^{\text {th }}$ growth sheath; MAT: Mean annual temperature; N: Nitrogen; NEFD: National Exotic Forest Description; NIWA: National Institute of Water and Atmosphere Research; $R$ : Ring number from pith at breast height; s, e: Model error terms

\section{Funding}

Funding to facilitate data analysis and publication of the model was provided by the Ministry for the Environment under Head Agreement Reference 20059, Statement of Work 21078.

\section{Availability of data and materials}

Please contact author for data requests.

\section{Authors' contributions}

PNB developed the concept for this manuscript and was the primary author. MOK developed the modelling approach, undertook the data analysis, and contributed to writing the paper. GRO and SHP undertook the biomass sampling and sample processing and contributed to writing the paper. All authors read and approved the final version of the manuscript.

\section{Authors' information}

PNB, a research scientist located at the New Zealand Forest Research Institute Ltd at Rotorua, undertakes research for the Ministry for the Environment, which is the agency responsible for reporting carbon stocks and changes in planted and natural forests in New Zealand.

\section{Ethics approval and consent to participate}

Not applicable

\section{Competing interests}

The authors declare that they have no competing interests.

\section{Publisher's Note}

Springer Nature remains neutral with regard to jurisdictional claims in published maps and institutional affiliations.

Received: 4 February 2018 Accepted: 2 May 2018

Published online: 08 June 2018

\section{References}

Beekhuis, J, \& Will, GM (1965). Regional variation in exotic forest productivity in New Zealand: Influencing factors. Proceedings of the Fourth N.Z. Geography Conference. Dunedin: New Zealand Geographic Society (Inc).

Beets, PN, Gilchrist, K, Jeffrey, MP. (2001). Wood density of radiata pine: effect of nitrogen supply. Forest Ecology and Management, 145, 173-180.

Beets, PN, Kimberley, MO, McKinley, RB. (2007). Predicting wood density of Pinus radiata annual growth increments. New Zealand Journal of Forestry Science, $37,241-266$

Beets, PN, Kimberley, MO, Paul, TSH, Garrett, LG. (2011). Planted forest carbon monitoring system - forest carbon model validation study for Pinus radiata. New Zealand Journal of Forestry Science, 41, 177-189.

Beets, PN, Robertson, KA, Ford-Robertson, JB, Gordon, J, Maclaren, JP. (1999). Description and validation of C-change: a model for simulating carbon content in managed Pinus radiata stands. New Zealand Journal of Forestry Science, 29, 409-427.

Brix, H. (1993): Fertilisation and thinning effect on a Douglas-fir ecosystem at Shawnigan Lake; a synthesis of project results. FRDA Report No. 196. Victoria, BC, Canada: Forestry Canada \& BC Ministry of Forests.

Cown, DJ, \& Clement, BC. (1983). A wood densitometer using direct scanning with X-rays. Wood Science and Technology, 17, 91-99.

Cown, DJ, McConchie, DL, Young, GD (1991). Radiata pine wood properties survey, FRI Bulletin no. 50 (revised edition). Rotorua: Ministry of Forestry.
Erickson, HD, \& Harrison, AT. (1974). Douglas-fir wood quality studies. Part I: effects of age and stimulated growth on wood density and anatomy. Wood Science and Technology, 8, 207-226.

Erickson, HD, \& Lambert, GMG. (1958). Effects of fertilisation and thinning on chemical composition, growth, and specific gravity of young Douglas-fir. Forest Science, 4, 307-315.

Harris, JM, \& Orman, HR (1958). The physical and mechanical properties of New Zealand grown Douglas-fir, New Zealand Forestry Service Technical Paper No. 24. Wellington: New Zealand Forest Service.

IPCC (2003). Good practice guidance for land use, land-use change, and forestry Kanagawa: Institute for Global Environmental Studies (IGES) for the IPCC.

Jozsa, LA, \& Brix, H. (1989). The effects of fertilisation and thinning on wood density of a 24-year-old Douglas-fir stand. Canadian Journal of Forest Research, 19, 1137-1145.

Kantavichai, R, Briggs, DG, Turnblom, EC. (2010). Effect of thinning, fertilization with biosolids, and weather on interannual ring specific gravity and carbon accumulation of a 55-year-old Douglas-fir stand in western Washington. Canadian Journal of Forest Research, 40, 72-85.

Kimberley, MO, McKinley, RB, Cown, DJ, Moore, JR. (2017). Modelling the variation in wood density of New Zealand-grown Douglas-fir. New Zealand Journal of Forestry Science, 47:15.

Knowles, RL. (2005). Development of a productivity index for Douglas-fir. New Zealand Journal of Forestry, 50, 19-22.

NEFD (2016). National Exotic Forest Description as at 1 April 2016. Wellington: Ministry for Primary Industries.

Smith, DM (1954). Maximum moisture content method for determining specific gravity of small wood samples, Forest Products Laboratory Report No. 2014. Madison: United States Department of Agriculture, Forest Service.

Stone, JK, Hood, IA, Watt, MS, Kerrigan, JL. (2007). Distribution of Swiss needle cast in New Zealand in relation in relation to winter temperature. Australasian Plant Pathology, 36, 445-454.

\section{Submit your manuscript to a SpringerOpen ${ }^{\circ}$ journal and benefit from:}

- Convenient online submission

- Rigorous peer review

- Open access: articles freely available online

- High visibility within the field

- Retaining the copyright to your article

Submit your next manuscript at springeropen.com 